\title{
O TRATADO DE MARRAQUEXE PARA FACILITAR O ACESSO A OBRAS PUBLICADAS ÀS PESSOAS CEGAS E SUA REPERCUSSÃO NO ORDENAMENTO JURÍDICO BRASILEIRO: CAUSAS DA MOROSIDADE NA ADAPTAÇÃO AO DIREITO INTERNACIONAL
}

Ivilla Nunes Gurgel ${ }^{1}$

\section{Resumo:}

Averigua-se a hipótese de que o ordenamento jurídico local é parcialmente compatível com o Tratado de Marraquexe para Facilitar o Acesso a Obras Publicadas às Pessoas Cegas, com Deficiência Visual ou Outras Dificuldades para Ter Acesso ao Texto Impresso, incorporado pelo Brasil em 2018 como emenda constitucional. São apresentadas as obrigações de direito internacional presentes no referido acordo e examinadas as leis pátrias de direitos autorais e circulação de obras escritas. Conclui-se que subsistem, inalterados, pontos contrários aos principais dispositivos do Tratado de Marraquexe, sendo a incongruência entre as normas interna e exterior um obstáculo ao seu cumprimento.

Palavras-chave: Direitos Autorais; Organização Mundial da Propriedade Intelectual; Direito Internacional; Pessoa com Deficiência; Acessibilidade

\section{THE MARRAKESH TREATY TO FACILITATE ACCESS TO PUBLISHED WORKS TO PERSONS WHO ARE BLIND AND ITS REPERCUSSION FOR BRAZILIAN LEGAL ORDER: CAUSES OF THE SLOW ADAPTATION TO THE INTERNATIONAL LAW}

\begin{abstract}
:
It is verified whether the local legal system is partially compatible with the Marrakesh Treaty to Facilitate Access to Published Works for the Blind, Visually Impaired or Otherwise Print Disabled, incorporated by Brazil in 2018 as a constitutional amendment. The obligations of international law present in the referred agreement are presented and the national laws of copyright and circulation of written works are examined. It is concluded that points contrary to the main provisions of the Marrakesh Treaty remain unaltered, with the incongruity between the internal and external norms being an obstacle to its fulfillment.

Keywords: Copyright; World Intellectual Property Organization; Persons with Disabilities; International Law; Accessibility
\end{abstract}

\section{Introdução}

Segundo a Organização Mundial da Propriedade Intelectual (OMPI), a propriedade intelectual consiste na garantia de posse exclusiva, detida pelo autor, artista ou inventor, daquilo que foi criado por ele e do controle de sua reprodução, assim como dos lucros

\footnotetext{
1 Discente do Mestrado em Constituição e Garantias de Direitos do Programa de Pós-Graduação em Direito da Universidade Federal do Rio Grande do Norte (PPGD/UFRN). Bacharela em Direito (UFRN). Advogada. Endereço eletrônico: ivillagurgel@gmail.com
} 
financeiros possíveis, gerando prerrogativas e deveres que constituem o direito da propriedade intelectual (WORLD INTELLECTUAL PROPERTY ORGANIZATION, 2020).

A prática das relações humanas tem registros antigos de salvaguarda aos direitos do autor ou inventor (BARBOSA, 2003, p. 41). ${ }^{2}$ Pensava-se à época, que assegurando a exclusividade de uso e lucro sob criações, estariam incentivando os demais poetas, chefs e artistas a empreenderem outras inovações e, consequentemente, se favorecerem do domínio limitado que lhes seria outorgado (BARBOSA, 2003, p. 42).

Contudo, a intensificação do fluxo de informações, bem como o trânsito de pessoas pelos territórios e continentes, tornou impossível acompanhar em tempo real as transações que ocorrem à volta do mundo. Em resposta a este panorama foram idealizadas e corporificadas as disposições da Convenção da União de Paris (CUP) de 1883 sobre propriedade industrial e, posteriormente, a Convenção da União de Berna (CUB) de 1886, centrada na propriedade intelectual (SEVILLE, 2018, p. 23).

Em que pese a maioria dos países, à época, já tratassem em seus ordenamentos sobre invenções e produções como propriedade daqueles que as concebessem, faltava garantir essa proteção às criações estrangeiras e às uniões que surgiram como ordenamento supranacional de apoio aos signatários (VIVANT; BRUGUIÈRE, 2009). Buscando corrigir essa contradição gerada pela variedade de legislações pátrias, as convenções propõem a comunhão de objetivos entre as nações-parte em torno das mesmas regras, ampliando a proteção aos direitos dos autores e inventores e universalizando as formalidades em relativas ao tratamento das criações desses, sejam elas materiais ou não (BRASIL, 1975). ${ }^{3}$

Os tratados, de Paris e Berna inauguraram o sistema internacional de proteção à propriedade intelectual e acabaram por se fundirem, no ano de 1893, em um organismo internacional denominado Escritórios Internacionais Unidos para a Proteção da Propriedade Intelectual (WORLD INTELLECTUAL PROPERTY ORGANIZATION, [2020a]). Atualmente, a regência do sistema internacional de proteção à propriedade intelectual cabe à Organização Mundial da Propriedade Intelectual (OMPI), a qual, desde 1967, administra um total de 26 tratados (WORLD INTELLECTUAL PROPERTY ORGANIZATION, [2020b]). ${ }^{4}$

\footnotetext{
2 “Considera-se a primeira de todas as propriedades intelectuais uma lei que vigorava na cidade grega de Síbaris, anteriormente ao ano 510 a.C., que protegia culinária de excelência e trabalhos artísticos excepcionais, proibindo a reprodução por parte de terceiros pelo período de um ano.” (BARBOSA, 2003, p. 41)

3 Artigo $1^{\circ}$ da Convenção da União de Paris de 1883 (BRASIL, 1975).

4 Os tratados sobre propriedade intelectual formam um sistema de garantias básicas compartilhados pelos Estados pactuantes, ao passo que os tratados que firmam sistemas globais versam sobre registros de propriedade
} 


\section{O TRATADO DE MARRAQUEXE PARA FACILITAR O ACESSO A OBRAS PUBLICADAS ÀS PESSOAS \\ CEGAS E SUA REPERCUSSÃO NO ORDENAMENTO JURÍDICO BRASILEIRO: \\ CAUSAS DA MOROSIDADE NA ADAPTAÇÃO AO DIREITO INTERNACIONAL}

A preocupação constante em limitar a prerrogativa de reprodução de uma criação é mais do que uma forma de garantir o retorno econômico aos criadores, trata-se da correção de um lapso do livre mercado. Em circunstâncias ideais, as forças do mercado atuariam sem embargo, havendo a distribuição proporcional de recursos e proveitos, todavia, a natureza impalpável dos bens imateriais facilita sua dispersão, pois eles podem ser reproduzidos indiscriminadamente por empresas ou pessoas físicas que detenham os meios mais eficazes para fazê-lo (BARBOSA, 2019). A imitação irrefreável retira, por completo, a vantagem econômica dos bens imateriais, que podem ser assimilados, utilizados e aproveitados por qualquer um, gerando um cenário de desvantagem financeira e desmotivação para autores e inventores.

Dessa forma, percebe-se o ramo em comento não existe apenas para incentivar produções, mas, na mesma medida, como forma de garantir que a geração de livros, filmes, peças, receitas e demais inventos não materiais sejam uma constante na sociedade humana (VIVANT, BRUGUIÈRE, 2009). A ausência de escassez intrínseca é o fundamento de existência da propriedade intelectual, que segue mantendo seus contornos clássicos, conferindo direitos limitados e territoriais centrados em um conteúdo específico relativo aos autores ou criadores de tal conteúdo ou, também, a terceiros associados (herdeiros, por exemplo). Tais direitos são definidos pela legislação interna dos Estados em associação com uma rede de normas internacionais de propriedade intelectual, cuja formação teve início no século XIX com os instrumentos de Paris e Berna (DREYFUSS; PILA, 2018, p. 05).

Ocorre que o sistema de propriedade intelectual, que existe para corrigir dessemelhanças na relação entre liberdade de mercado e criações imateriais, acaba gerando e acentuando desigualdades de ordem informacional. Quando é restrita a livre circulação de produções acadêmicas, literárias, teatrais e outras, limita-se automaticamente o acesso à informação, que só poderá ser obtida mediante a aquisição dos bens imateriais exemplificados. Essa retenção de acesso aos meios de educação e conhecimento é contornada de diversas formas, com a existência de bibliotecas, sebos, arquivos digitais ou disponibilização de livros como de domínio público.

Ainda assim, prevalece a desarmonia entre a quantidade de escritos publicados e o número de pessoas que podem acessar esses materiais, especialmente quando se trata da

intelectual, unificando processos e custos. Por sua vez, os tratados sobre classificação criam sistemas de gerência de informações relativas a invenções, marcas registradas e designs industriais, centralizando dados sobre essas subáreas (WORLD INTELLECTUAL PROPERTY ORGANIZATION, [2020b]). 
publicação e circulação de materiais escritos em formato adaptado para serem lidos por pessoas com deficiência visual - dentre o número de obras publicadas anualmente, apenas uma porcentagem entre 1 a $7 \%$ é adaptada para esse público, estimado em 2.2 bilhões de pessoas (WORLD HEALTH ORGANIZATION, 2020). Estima-se, ainda, que chega a 5\% a quantidade de livros adaptados ao sistema Braille em nações desenvolvidas, ao passo que, em países em desenvolvimento, esse percentual fica em torno de 1\% (TOKARNIA, 2019). No Brasil, $61 \%$ dos leitores com imparidades visuais atribuem nota 6 ou menos à facilidade de encontrar exemplares adaptados no mercado e o país está abaixo da média nas economias emergentes em produção e adaptação de livros para formatos especiais (SETOR3, 2019).

Esse cenário não escapou à percepção do sistema internacional de proteção à propriedade intelectual, que se vem se dedicando a debater acerca da relação entre propriedade intelectual e direitos humanos (DREYFUSS; PILA, 2018, p. 11-12). Anos de discussões culminaram na concepção do Tratado de Marraquexe para Facilitar o Acesso a Obras Publicadas às Pessoas Cegas, com Deficiência Visual ou com Outras Dificuldades para Ter Acesso ao Texto Impresso. Adotado em 2013, ele propõe que seus signatários criem exceções aos direitos de cópia domésticos, facilitando a adaptação de trabalhos escritos para formatos acessíveis, não apenas para o Sistema Braille, disponíveis a todos os que tiverem dificuldades visuais em qualquer grau ou tipo. Além disso, são estabelecidas as bases para a realização de um intercâmbio transfronteiriço e não oneroso dos exemplares adaptados.

O presente trabalho analisa a adaptação do Tratado de Marraquexe à legislação brasileira. Atendo-se o status de emenda constitucional, parte-se da premissa de que o ordenamento pátrio está parcialmente de acordo com o pactuado no plano internacional, o que será demonstrado ressaltando a caducidade de disposições da Lei de Direitos autorais (Lei no 9.610 de 1998), da Política Nacional do Livro (Lei n ${ }^{\circ} 10.753$ de 2003) e da Política Nacional de Leitura e Escrita (Lei n ${ }^{\circ} 13.696$ de 2018) em comparação com o texto internacional, sendo este desalinhamento entre o direito internacional e o direito interno a justificativa do trabalho desenvolvido.

\section{As obrigações assumidas pelo Brasil no Tratado de Marraquexe de 2013}

A agregação dos direitos da pessoa com deficiência e dos direitos de cópia em um único instrumento gera, além de obrigações específicas, noções e terminologias até então 
desconhecidas, mas fundamentais para a compreensão do que é proposto pelo instrumento em comento. O Tratado de Marraquexe visa garantir o acesso pleno a conteúdos escritos, por qualquer indivíduo com deficiência que impossibilite a leitura eficaz de material impresso, sujeitos que o tratado nomeia como "beneficiários". Esse termo comporta tanto quem apresenta deficiência visual em qualquer grau, quanto aqueles que não podem segurar e manusear um livro em decorrência de limitações motoras (BRASIL, 2018a). ${ }^{5}$

Adstritos ao conceito de "beneficiário" estão os termos "obras" e "exemplar em formato acessível", ambos aludem aos materiais escritos, partes fundamentais do intercâmbio transfronteiriço proposto pelo Tratado de Marraquexe (BRASIL, 2018a). ${ }^{6}$ Entendem-se por “obras" os materiais literários e artísticos publicados ou disponibilizados em qualquer formato (incluindo áudios), ao passo que "exemplares em formato acessível" equivalem à reprodução de uma obra em formato alternativo ao original, que viabilize o acesso confortável por um beneficiário, neutralizando o impacto de qualquer limitação comprometedora da leitura (WORLD INTELLECTUAL PROPERTY ORGANIZATION, 2016).

As nações que assentiram com o disposto no Tratado de Marraquexe se vinculam a duas obrigações principais, de adaptação do direito interno e, sucessivamente, a obrigação de fazer. Os deveres de adotar e respeitar as nomenclaturas detalhadas supra e constituir (ou designar) uma entidade autorizada preestabelecem a incumbência de modificar os preceitos domésticos de direitos autorais para permitir a conversão não onerosa de livros em formato tradicional para formatos alternativos. O cumprimento dos ajustes ao direito pátrio, por sua vez, deve possibilitar a satisfação da obrigação de promover um intercâmbio dos livros adaptados entre os países parte do acordo.

Ao examinar as principais obrigações do tratado e considerando a proteção às obras escritas garantida pelo Estado brasileiro, percebe-se que, apesar de já existir previsão legal de gratuidade na adaptação do formato de materiais textuais, a legislação pátria ainda está em déficit em relação às previsões do Tratado. Essa diferença existe porque, em que pese o documento internacional traga somente duas obrigações principais, cada uma delas comporta minúcias que, se detalhadas, desvelam tanto funcionamento do instrumento quanto,

\footnotetext{
${ }^{5}$ Art. $3^{\text {o }}$ do Tratado de Marraqueche para Facilitar o Acesso a Obras Publicadas às Pessoas Cegas, com Deficiência Visual ou com Outras Dificuldades para Ter Acesso ao Texto Impresso (BRASIL, 2018a).

6 Art. $2^{\circ}$ do Tratado de Marraqueche para Facilitar o Acesso a Obras Publicadas às Pessoas Cegas, com Deficiência Visual ou com Outras Dificuldades para Ter Acesso ao Texto Impresso (BRASIL, 2018a).
} 
principalmente, os pontos a serem incorporados ao ordenamento brasileiro, mediante a atuação do Poder Legislativo.

\subsection{A obrigação de disponibilização gratuita de obras escritas}

O Tratado de Marraquexe estabelece sua primeira obrigação, de adaptação das normas internas, ao deixar a cargo das nações pactuantes o dever de fixarem, em suas respectivas legislações nacionais atinentes aos direitos do autor, desvios que permitam a reprodução e disponibilização gratuitas de obras escritas para aqueles que se enquadram como beneficiários. Essa limitação ou isenção legal deve incluir a possibilidade de adaptação do objeto para torná-lo acessível e é viável, também, abrir exceções aos direitos de representação ou execução pública para cumprir com a propositura em comento (BRASIL, 2018a). ${ }^{7}$

Para atender ao disposto acima, o Tratado estabelece que as exceções aos direitos autorais empreendidas pelos países signatários só estarão em consonância com aquilo que foi pactuado caso incorporem orientações específicas, também contidas no instrumento. A limitação às legislações nacionais, em que pese dependa da iniciativa e comprometimento de cada nação, deve permitir que a cópia e disponibilização do material adaptado não estejam vinculadas ao criador da obra, que é excluído da operação proposta. A obra adaptada deverá ser ofertada ao beneficiário por qualquer meio, inclusive cabendo isenção de custos (BRASIL, 2018a).

Para que o beneficiário adquira, de fato, um livro adaptado nos termos do Tratado de Marraquexe, a entidade responsável pela adaptação e concessão deve ter acesso legal ao material escrito que, por sua vez, deve sofrer mudanças que visem somente sua adaptação para que a informação nele contida seja acessível. Os frutos dessa atividade sem fins lucrativos são destinados exclusivamente aos beneficiários, que podem, também, adaptar por conta própria ou com auxílio de indivíduo responsável por seu cuidado exemplares de obras para um formato acessível, desde que o material base seja lícito. Obras de difícil aquisição em razão de serem raras ou de alto valor comercial podem ser excluídas da modificação e distribuição postas pelo Tratado, cabendo ao Estado parte informar o diretor geral da OMPI caso precise fazer uso dessa faculdade (BRASIL, 2018a).

\footnotetext{
7 Art. $4^{\circ}$ do Tratado de Marraqueche para Facilitar o Acesso a Obras Publicadas às Pessoas Cegas, com Deficiência Visual ou com Outras Dificuldades para Ter Acesso ao Texto Impresso (BRASIL, 2018a).
} 
O instrumento elenca um rol de elementos que devem ser incorporados à legislação interna das nações pactuantes sob a forma de exceções aos direitos do autor, mas essa listagem de disposições é exemplificativa, constituindo um núcleo essencial para a concretização do que é estabelecido nessa primeira obrigação. Os pormenores atrelados à proposta de adaptação trazida pelo Tratado devem servir de norte para eventuais limitações adicionais aos direitos do autor, pois as partes não estão vinculadas apenas às bases detalhadas supra, essas são, tão somente, um ponto de partida, sendo possível a expansão ou diversificação destas limitações, desde que em harmonia com o Tratado de Marraquexe (BRASIL, 2018a). ${ }^{8}$

\subsection{A obrigação de intercâmbio entre estados partes}

A segunda obrigação principal posta pelo Tratado está intimamente vinculada às restrições e exceções às leis nacionais relativas aos exemplares em edição acessível. O intercâmbio transfronteiriço desses exemplares em formato apropriado só pode ocorrer caso esses materiais sejam, de fato, gerados. A cópia de um material em configuração acessível, cuja produção tenha sido viabilizada pelas exceções previstas pelo Tratado, poderá ser cedida ou emprestada, pelo órgão competente para tal, a outra nação-parte signatária do pacto ou à entidade competente localizada em seu território, iniciando-se uma importação mútua e não onerosa das produções reformadas (BRASIL, 2018a). ${ }^{9}$

O Tratado estabelece que essa troca de materiais também deve estar prevista na exceção adotada em relação aos direitos do autor domésticos de cada país, podendo ser operacionalizada por entidade autorizada e sem o acompanhamento do criador do material em questão. Ao receberem as cópias adaptadas, as partes se comprometem a manter a exclusividade de reprodução e distribuição reservada aos beneficiários, nos termos do próprio Tratado de Marraquexe e da Convenção de Berna de 1886 (BRASIL, 2018a). ${ }^{10}$

A distribuição ou disponibilização de livros nos termos da proposta de intercâmbio é limitada à jurisdição do Tratado, ressalvado o respeito a obrigações provenientes de outros

\footnotetext{
8 Art. $4^{\circ}$ do Tratado de Marraqueche para Facilitar o Acesso a Obras Publicadas às Pessoas Cegas, com Deficiência Visual ou com Outras Dificuldades para Ter Acesso ao Texto Impresso (BRASIL, 2018a).

9 Art. $5^{\circ}$ do Tratado de Marraqueche para Facilitar o Acesso a Obras Publicadas às Pessoas Cegas, com Deficiência Visual ou com Outras Dificuldades para Ter Acesso ao Texto Impresso (BRASIL, 2018a).

10 Art. $5^{\circ}$ do Tratado de Marraqueche para Facilitar o Acesso a Obras Publicadas às Pessoas Cegas, com Deficiência Visual ou com Outras Dificuldades para Ter Acesso ao Texto Impresso (BRASIL, 2018a).
} 
pactos administrados pela Organização Mundial da Propriedade Intelectual que, eventualmente, reduzam a abrangência das exceções propostas. Finalizando as disposições principais à respeito da transação de materiais, é posto que o intercâmbio de livros adaptados deve, em termos de quantidade, ser paritário entre as partes, que devem receber o mesmo número de materiais que forneceram para importação à(s) outra(s) parte(s), sendo ressaltada a obrigação expressa de proteger a privacidade de todos os beneficiários envolvidos em qualquer etapa (BRASIL, 2018a). ${ }^{11}$

Mesmo propondo e estruturando a efetivação da isenção ao direito de propriedade intelectual e o câmbio de livros textos adaptados, o Tratado de Marraquexe acaba por inclinarse à omissão justo em um ponto crucial da atualidade: os meios tecnológicos. A reprodução de textos através de tecnologias de informação e comunicação não é detalhada na redação do Tratado, circunstância que pode vir a limitar significativamente sua utilidade atualmente, em virtude do protagonismo da internet como meio de disseminação e troca de informações através de celulares, computadores e demais tecnologias de informação e comunicação (TIC) (LI, 2015, p. 383-384).

As alterações legais e a permuta de materiais entre as nações, obrigações principais do Tratado de Marraquexe, são complementares entre si, sendo insuficiente, para promover eficazmente o acesso à leitura, que apenas uma das medidas seja concretizada. Em atenção à necessidade de materialização quase simultânea de determinações distintas, mas conexas, são apontadas entidades competentes para orientação e fiscalização do cumprimento das obrigações. O monitoramento se faz necessário não apenas para sanar dúvidas e garantir a obediência da norma internacional, mas, sobretudo, para segurar que a harmonia entre os deveres, observada no texto, será mantida de fato.

\subsection{Mecanismos de monitoramento e a livre escolha dos estados}

A materialização de somente uma das duas obrigações principais do Tratado de Marraquexe esvazia o instrumento internacional do sentido que lhe fundamenta. Procurando evitar esse destino, são apontadas instituições que se ocuparão de promover ou fiscalizar a realização das metas positivadas.

\footnotetext{
11 Art. $8^{\circ}$ do Tratado de Marraqueche para Facilitar o Acesso a Obras Publicadas às Pessoas Cegas, com Deficiência Visual ou com Outras Dificuldades para Ter Acesso ao Texto Impresso (BRASIL, 2018a).
} 


\section{O TRATADO DE MARRAQUEXE PARA FACILITAR O ACESSO A OBRAS PUBLICADAS ÀS PESSOAS \\ CEGAS E SUA REPERCUSSÃO NO ORDENAMENTO JURÍDICO BRASILEIRO: \\ CAUSAS DA MOROSIDADE NA ADAPTAÇÃO AO DIREITO INTERNACIONAL}

Ao trazer as definições de termos próprios do tratado, é identificada a "entidade autorizada", que consiste em um órgão reconhecido ou autorizado pelo governo a promover, gratuitamente, o acesso à educação, formação pedagógica, leitura adaptada e acesso à informação àqueles identificados como beneficiários, nos termos do Tratado (BRASIL, 2018a). ${ }^{12}$

Cabe à entidade autorizada, além de lidar com os beneficiários e a distribuir, controladamente, cópias dos escritos adaptados, desencorajar a reprodução ilegal de obras imateriais escritas. Apesar de serem atribuídas à entidade autorizada uma definição breve e finalidades moderadas, identificam-se menções a este instituto em quase todos os artigos do Tratado, tornando inegável o caráter fundamental que possuem enquanto viabilizadoras do cumprimento das obrigações pactuadas (BRASIL, 2018a). ${ }^{13}$

Essa qualidade medular da entidade autorizada não se explica somente por sua relação com outros órgãos e iniciativas de monitoramento postas pelo Tratado de Marraquexe. A entidade autorizada acumula duas funções, sendo um órgão de cumprimento e de monitoramento, simultaneamente. Ao passo que as mudanças na legislação de direito autoral de cada país parte irão depender da organização política e legislativa nacionais, o cumprimento da obrigação de adaptar e distribuir livros em formato acessível cabe unicamente à entidade autorizada. Essa última deve, ainda, concorrentemente, supervisionar e registrar o fluxo das obras escritas, mantendo atualizações sobre o uso e cuidado das mesmas, além de vigiar o respeito à propriedade intelectual, sendo essa gerência de informação uma incumbência de natureza nitidamente fiscalizatória se comparada com o encargo de adaptar e difundir livros a nível regional e global, que presume mais esforços e resultados palpáveis (BRASIL, 2018a).

Os dados coletados e mantidos pelas entidades autorizadas de cada nação são fundamentais para que a cooperação entre as partes contratantes ocorra. O Tratado estabelece que as nações pactuantes devem colaborar umas com as outras ajudando suas respectivas entidades a fornecer, voluntariamente, àqueles interessados, informações relativas às práticas e políticas adotadas para efetivar o intercâmbio de exemplares tornados acessíveis. A cooperação envolve, também, o próprio Escritório Internacional da OMPI, que é convocado a

\footnotetext{
${ }^{12}$ Art. $2^{\circ}$, (c), do Tratado de Marraqueche para Facilitar o Acesso a Obras Publicadas às Pessoas Cegas, com Deficiência Visual ou com Outras Dificuldades para Ter Acesso ao Texto Impresso (BRASIL, 2018a).

${ }^{13}$ Art. $2^{\circ}$, do Tratado de Marraqueche para Facilitar o Acesso a Obras Publicadas às Pessoas Cegas, com Deficiência Visual ou com Outras Dificuldades para Ter Acesso ao Texto Impresso (BRASIL, 2018a).
} 
compartilhar informações sobre o tratado em questão e a criar um ponto de acesso aos dados armazenados pelas entidades de cada nação (BRASIL, 2018a). ${ }^{14}$

Além de um órgão da Organização Mundial da Propriedade Intelectual para auxiliar na implementação dos objetivos contidos no tratado e compilar seus desdobramentos, está prevista, ainda, a instituição de uma Assembleia para manter e observar o progresso do Tratado de Marraquexe de 2013. Composta por um delegado de cada país membro, cabe a este organismo deliberar sobre eventuais revisões ao tratado e decidir sobre a admissão de entidades não governamentais como partes, seguindo suas próprias regras e reunindo-se mediante convocação do Diretor Geral da OMPI (BRASIL, 2018a). ${ }^{15}$

Por outro lado, a responsabilidade de atentar para eventuais questões administrativas (e executá-las, se necessário) é direcionada ao Escritório Internacional da Organização, que exerce tarefas secretariais sob a chefia do Diretor Geral em exercício (ORGANIZAÇÃO MUNDIAL DA PROPRIEDADE INTELECTUAL, 2002). ${ }^{16}$ A união de entidades tradicionais, como o Escritório Internacional, com entidades contemporâneas, concebidas junto com Tratado de Marraquexe, resultam em uma rede de órgãos de cumprimento e monitoramento que são, claramente, interdependentes, uma vez que devem cambiar informações entre si com o fito compartilhar os avanços de cada nação rumo à satisfação integral do que foi pactuado.

Essa troca de dados também é fundamental para equalizar os progressos de cada país parte do acordo, uma vez que os mais avançados na realização das metas propostas revelarão informações de suas trajetórias para auxiliar aqueles que estejam, de alguma forma, obsoletos. Essa atenção às diferenças permite uma melhor adequação dos países signatários às exigências do Tratado de Marraquexe, sendo útil tanto para as partes detentoras de legislação defasada em relação à evolução da propriedade intelectual, quanto para as partes cuja norma doméstica seja, parcial ou completamente, vanguardista em matéria de direitos do autor, como é o caso do Brasil.

O Tratado de Marraquexe reconhece a possível preexistência de exceções ou limitações aos direitos de cópia no direito interno de Estados membros da OMPI, sendo um

\footnotetext{
${ }^{14}$ Art. $9^{\circ}$ do Tratado de Marraqueche para Facilitar o Acesso a Obras Publicadas às Pessoas Cegas, com Deficiência Visual ou com Outras Dificuldades para Ter Acesso ao Texto Impresso (BRASIL, 2018a).

${ }^{15}$ Art. $13^{\circ}$ do Tratado de Marraqueche para Facilitar o Acesso a Obras Publicadas às Pessoas Cegas, com Deficiência Visual ou com Outras Dificuldades para Ter Acesso ao Texto Impresso (BRASIL, 2018a).

${ }^{16}$ Artigo $9^{\circ}$ da Convenção que institui a Organização Mundial da Propriedade Intelectual (ORGANIZAÇÃO MUNDIAL DA PROPRIEDADE INTELECTUAL, 2002).
} 


\section{O TRATADO DE MARRAQUEXE PARA FACILITAR O ACESSO A OBRAS PUBLICADAS ÀS PESSOAS \\ CEGAS E SUA REPERCUSSÃO NO ORDENAMENTO JURÍDICO BRASILEIRO: \\ CAUSAS DA MOROSIDADE NA ADAPTAÇÃO AO DIREITO INTERNACIONAL}

mecanismo harmonizador das diferenças de legislações nacionais (BRASIL, 2018a). ${ }^{17}$ Essa compatibilização é necessária, pois exceções já previstas em ordenamentos domésticos, ainda que em consonância com o Tratado, não resolvem o problema da carência global de livros adaptados, que é o cerne do pacto em comento. Isso demanda, por parte dos países que já prevêem exceções ou limitações às leis de direito do autor, a iniciativa de prosseguir com a implementação das demais disposições para que a celeuma da insuficiência generalizada de livros possa ser sanado, como objetiva o tratado em comento.

Essa é, precisamente, a situação na qual o Estado brasileiro se encontra, uma vez que sua legislação atinente aos direitos do autor permite a reprodução de obras literárias, artísticas ou científicas em formato adaptado, mas é silente em relação a outros pontos presentes no Tratado de Marraquexe, tais como a onerosidade, o intercâmbio transfronteiriço, os beneficiários e a vinculação do autor e seus sucessores às movimentações de sua criação. Ao se comprometer com o disposto no Tratado de Marraquexe, o Brasil, tal como outras nações e atores da sociedade internacional, se associou com a OMPI para sanar a escassez de livros adaptados através da concretização de ações específicas, que devem ser adotadas por completo em território pátrio, existindo, portanto, a obrigação de elucidar quaisquer omissões normativas para satisfazer os objetivos acordados no plano internacional.

\section{A morosidade no alinhamento do direito brasileiro às prescrições internacionais}

Admite-se que exceções já existentes são insuficientes para sanar a permanente escassez de livros em formato acessível àqueles que portam imparidades visuais, de forma que o advento do Tratado de Marraquexe, enquanto um marco jurídico internacional foi o meio escolhido pela Organização Mundial da Propriedade Intelectual para desfazer um obstáculo de nível mundial através da cooperação transnacional dos pactuantes.

Pressupõe-se, então, que os contratantes estejam cientes do dever de adequar seus respectivos ordenamentos às avenças internacionais às quais tenham, espontaneamente, aderido. Para além da pura ciência, a iniciativa de desencadear esse ajustamento entre normas a partir da entrada em vigor do Tratado é ideal, pois elimina o risco de uma lei nacional

\footnotetext{
17 Preâmbulo do Tratado de Marraqueche para Facilitar o Acesso a Obras Publicadas às Pessoas Cegas, com Deficiência Visual ou com Outras Dificuldades para Ter Acesso ao Texto Impresso (BRASIL, 2018a)..
} 
embargar a execução do que foi combinado no seio da OMPI, o que frustraria a cooperação almejada e contribuiria para a manutenção do problema que se busca resolver.

Nesse ínterim, o Estado brasileiro outorgou ao Tratado de Marraquexe de 2013 o status de emenda constitucional, pois seu texto passou pelo rito previsto no art. $5^{\circ}, \S 3^{\circ}$, da Constituição Federal, sendo submetido à aprovação, em dois turnos, por três quintos dos votos dos integrantes de cada casa do Congresso Nacional, compondo, assim, o bloco de constitucionalidade. A integração do Tratado de Marraquexe ao panteão das normas constitucionais é um dos fundamentos de sua superioridade em relação às leis infraconstitucionais do Brasil, contudo, a materialização dessa hierarquia formal depende do esforço político e jurídico de proceder à modificação ou extinção de dispositivos que estejam em desacordo com o compromisso transnacional, firmado no âmbito da Organização Mundial da Propriedade Intelectual (OMPI).

A legislação atinente aos direitos do autor e à distribuição de obras literárias deve, então, estar em harmonia com o tratado em comento, para que os propósitos do mesmo sejam realizados. Essa confluência, contudo, não é observada quando comparado o sistema brasileiro de proteção ao direito do autor com o Tratado de Marraquexe, sendo identificáveis contrariedades desde artigos iniciais da Constituição Federal até a normativa infraconstitucional mais recente relativa aos direitos autorais.

A tarefa de corrigir as contraposições entre a norma internacional e as normas internas cabe ao Poder Legislativo, consubstanciado no Congresso Nacional, responsável pela criação e revisão das leis propostas no âmbito de qualquer uma de suas casas, a Câmara dos Deputados e o Senado Federal. Ainda que o Brasil seja uma das nações autoras do texto do Tratado de Marraquexe de 2013, e que o mesmo esteja em vigor no plano interno desde 2018, a regulamentação de sua aplicação ocorre muito lentamente. Anos após a entrada em vigor do Tratado, uma minuta de decreto regulamentador segue em fase de edição, e o instrumento internacional, que integra o bloco de constitucionalidade, ainda não conta com base legal para que suas disposições sejam concretizadas em decorrência da atuação morosa do poder público.

\subsection{A exclusividade da propriedade intelectual segundo o art. $5^{\circ}$, XXVII}


Um cenário de disparidade entre a norma interna e o compromisso internacional ratificado é sinônimo de complicações iminentes. No caso do Brasil, a obsolescência do sistema nacional de direitos do autor, em relação ao que foi acordado no Tratado de Marraquexe, revela a inconstitucionalidade dessas normas nacionais, que não estão adequadas tanto ao tratado internacional per se, quanto àquilo que o instrumento representa uma vez acomodado na trama normativa brasileira como integrante do bloco de constitucionalidade.

A primeira colisão entre o Tratado incorporado e o ordenamento interno reside ainda na própria esfera das normas constitucionais. A Constituição Federal de 1988, supedâneo de todo o repertório legal brasileiro, concede ao autor de obra literária o direito fundamental de exclusividade de utilização, publicação e reprodução de seus escritos, bem como a transmissão dessa prerrogativa aos seus herdeiros pelo tempo previsto em lei (BRASIL, 1988). ${ }^{18}$ Por sua vez, de maneira oposta, o Tratado de Marraquexe prima pela independência da obra, estabelecendo a desvinculação do autor e de seus herdeiros do processo de adaptação e intercâmbio dos livros.

A correção dessa dissonância, visando à adequação ao tratado internacional, importa na imposição da exclusão do autor e seus sucessores do processo desenvolvido pelas entidades autorizadas. Embora o acompanhamento, em tempo real, da adaptação e do intercâmbio de livros seja restrito aos órgãos habilitados, o dever de registrar todo o procedimento e publicizar tais informações permite que a separação entre o autor e a obra não adquira caráter confidencial, pois o criador pode tomar conhecimento dos pormenores relativos à adaptação e destinação do seu trabalho.

A exclusividade de utilização, publicação e reprodução conferida ao autor e seus legatários pela Constituição Federal brasileira é aprofundada por normas infraconstitucionais, as quais alteram e atualizam os direitos do autor e os que lhes são conexos, trazendo situações e exceções não abordadas no texto constitucional. Por isso, em que pese a clara dissidência entre o expresso no Tratado de Marraquexe de 2013 e o inciso XXVII da Constituição Federal de 1988, o disposto na Constituição apenas abre a matéria, de forma que uma eventual modificação da redação da Carta Magna não impactaria significativamente o amoldamento da norma pátria ao compromisso internacional, visto que outros diplomas legais, como a Lei $\mathrm{n}^{\circ}$ 9.610 de 1998 (especialmente seus artigos 30 e 46), tratam os direitos autorais com mais profusão, como será exposto a fio.

${ }^{18}$ Art. 5º, XXVII da Constituição da República Federativa do Brasil de 1988 (BRASIL, 1988). 


\subsection{As lacunas da Lei de Direitos Autorais em relação aos beneficiários e autores}

A propriedade intelectual manifesta-se, sumariamente, no rol de Direitos e Garantias Fundamentais da Constituição Federal brasileira que, por sua vez, reflete as previsões da Declaração Universal dos Direitos Humanos de 1948 sobre a matéria (ORGANIZAÇÃO DAS NAÇÕES UNIDAS, [1948]). ${ }^{19}$ Amparada por esses escritos, a Lei no 9.610 de 1998 dispõe sobre a proteção moral e material de trabalhos escritos, concebendo especificidades que ultrapassam o caráter basilar das previsões decorrentes da Constituição Federal de 1988 e do Tratado de direitos humanos mencionado supra e traz, inclusive, exceções a tais regras fundamentais.

O aspecto transcendental da Lei de Direitos Autorais ajusta-se diretamente com o Tratado de Marraquexe, pois os dois diplomas legais detalham e criam reservas em relação às normas gerais sobre direitos do autor, motivo pelo qual o ordenamento infraconstitucional deve ser alvo da adaptação ao compromisso internacional. A Lei nº 9.610 de 1998, apesar de não fornecer uma definição precisa do objeto da proteção autoral, já contém previsão expressando que não ofende os direitos de cópia e reprodução, sem fins comerciais, de obra literária em qualquer formato adaptado para deficientes visuais, que coincide com um dos mandamentos centrais do Tratado de Marraquexe (RODRIGUES, 2019).

Apesar do caráter progressista da exceção já contida na Lei nº 9.610 de 1998, o Tratado guarda outras especificidades que não encontram correspondência na Lei de Direitos Autorais brasileira, motivo pelo qual essa deve ser modificada, sendo incluídas as previsões concordadas no plano da OMPI.

Em que pese a vanguarda do legislador brasileiro ao antecipar uma das principais regras do Tratado de Marraquexe de 2013, a Lei de Direitos autorais destina, somente para pessoas com deficiência visual a reprodução gratuita de livros adaptados, que não constitui ofensa aos direitos do autor (BRASIL, 1998). ${ }^{20}$ A limitação do destino dos livros em formato especial apenas para pessoas cegas consiste em um descompasso em relação ao Tratado internacional, que favorece um rol muito mais amplo de pessoas com deficiência, os

\footnotetext{
19 “Todo ser humano tem direito à proteção dos interesses morais e materiais decorrentes de qualquer produção científica literária ou artística da qual seja autor.” Art. XXVII, 2 da Declaração Universal dos Direitos Humanos (ORGANIZAÇÃO DAS NAÇÕES UNIDAS, [1948]).

${ }^{20}$ Art. 46, I, alínea d), da Lei n 9.610, de 19 de fevereiro de 1998 (BRASIL, 1998).
} 


\section{O TRATADO DE MARRAQUEXE PARA FACILITAR O ACESSO A OBRAS PUBLICADAS ÀS PESSOAS \\ CEGAS E SUA REPERCUSSÃO NO ORDENAMENTO JURÍDICO BRASILEIRO: \\ CAUSAS DA MOROSIDADE NA ADAPTAÇÃO AO DIREITO INTERNACIONAL}

chamados "beneficiários" (BRASIL, 2018). ${ }^{21}$ Essa dissonância entre os tutelados pelo Tratado e os favorecidos pela exceção na lei brasileira denuncia que esta última carece do caráter global que o instrumento mais recente oferece.

O Tratado de Marraquexe, ao contrário da lei brasileira, propõe que o livro seja adaptado e acessível para qualquer pessoa que porte deficiência perturbadora da leitura, ou seja, além de cegos, estão abarcados quem tenha deficiência visual ou outra deficiência de captação ou de leitura que não possa ser remediada e, também, quem esteja impossibilitado, por deficiência física, de sustentar ou manusear um livro de forma apropriada para a leitura. A harmonização da Lei n ${ }^{\circ} 9.610$ de 1998 ao compromisso internacional impõe a expansão do rol de destinatários dos livros em formato especial, coadunando com o caráter inclusivo do Tratado. Tal ampliação não visa somente a concordância formal entre normas, ela garante que os materiais recebidos em decorrência da cooperação transnacional serão disponibilizados democraticamente a todos que necessitarem, e não serão de acesso restrito à somente um grupo de pessoas, situação que conservaria a carência mundial de livros.

Na mesma senda, a Lei de Direitos autorais brasileira, apesar de não se debruçar sobre a comercialização internacional de livros, garante ao autor a prerrogativa de disponibilizar a obra para reprodução no local desejável e pelo tempo que achar razoável (BRASIL, 1998). ${ }^{22}$ Ocorre que, segundo o Tratado de Marraquexe, uma vez cedendo o livro para adaptação a uma entidade autorizada, o autor não poderá acompanhar as mudanças em tempo real, não podendo, também, interferir nesse processo em nenhuma fase, tampouco desfazê-lo, uma vez concluído. Nesse ponto, porém, a norma de direitos autorais trata, de forma resumida, de um tópico melhor desenvolvido na Lei $\mathrm{n}^{\mathrm{o}} 10.753$ de 2003 (Política Nacional do Livro) que detalha a distribuição de livros nacionais em território pátrio e estrangeiro e que, por si só, também possui semelhanças e dissonâncias em relação ao Tratado de Marraquexe de 2013.

Concisamente, por conter restrições que conflitam com as diretrizes contidas no Tratado de Marraquexe, a lei de direitos do autor brasileira encontra-se incompatível com o direito internacional e, ao mesmo tempo, com o direito constitucional, visto que o Tratado integra o bloco de constitucionalidade em razão do rito especial de sua ratificação. A demora

\footnotetext{
${ }^{21}$ Art. $3^{\mathbf{o}}$ do Tratado de Marraqueche para Facilitar o Acesso a Obras Publicadas às Pessoas Cegas, com Deficiência Visual ou com Outras Dificuldades para Ter Acesso ao Texto Impresso (BRASIL, 2018a).

${ }^{22}$ Art. 30 da Lei nº 9.610 de 19 de fevereiro de 1998 (BRASIL, 1998).
} 
em editar ou criar exceções aos pontos caducos da Lei 9.610 de 1998 consiste em um descumprimento ao compromisso internacional assumido pelo Brasil, além de atingir os direitos das pessoas com deficiência, que continuam tendo sua formação intelectual prejudicada em razão da escassez de opções de leitura apropriadas para suas imparidades.

\subsection{Inadequações da Política Nacional do Livro em relação ao Tratado de Marraquexe de 2013}

Enquanto a Lei de Direitos autorais pormenoriza a exclusividade do autor sobre seus escritos, a Lei $n^{\circ} 10.753$ de 2003, denominada de Política Nacional do Livro (PNL) cuida da difusão, circulação e distribuição dos frutos do trabalho do autor em território nacional e estrangeiro. A PNL não traz aspectos de propriedade intelectual, mas se relaciona com a matéria, pois disciplina a disseminação e o aproveitamento econômico de obras escritas, que são pontos fundamentais, também, do Tratado de Marraquexe de 2013.

A Lei ${ }^{\circ} 10.753$ de 2003 confere às obras nacionais, convencionais ou adaptadas, a condição de produtos, cuja produção deve ser fomentada e estimulada a ter condições de competir no mercado internacional, tornando o Brasil um centro editorial relevante mediante a exportação de livros nacionais (BRASIL, 2003). ${ }^{23} \mathrm{O}$ mesmo instrumento se propõe, ainda, a garantir o acesso à leitura às pessoas com deficiência visual, mas não apresenta medidas para a concretização desse objetivo (BRASIL, 2003). ${ }^{24}$

A PNL, ao mesmo tempo que mercantiliza o livro nacional, não prevê nenhuma possibilidade de circulação não onerosa de livros adaptados, em versão física ou em áudio, para portadores de imparidades visuais. Tal contexto restringe os leitores às opções de comprarem o material escrito em livrarias ou esperarem sua disponibilização em biblioteca ou domínio público. Todavia, sabendo que menos de $10 \%$ das milhares de publicações anuais são adaptadas para formatos acessíveis, resta claro que um sujeito com limitações visuais tem o seu direito de acesso à leitura obstaculizado, pois está circunscrito a uma parcela diminuta de livros disponíveis para seu consumo (WORLD BLIND UNION, 2016).

Constata-se, então, que a Lei n 10.753 de 2003 acaba por corroborar com a problemática da escassez global de livros e contradiz a si mesma, visto que não contribui com nada além da mera promessa inócua de assegurar o acesso à leitura para pessoas cegas.

\footnotetext{
${ }^{23}$ Art. $^{\circ}$ da Lei ${ }^{\circ} 10.753 / 2003$ (Política Nacional do Livro) (BRASIL, 2003).

${ }^{24}$ Art. $1^{\circ}$ da Lei ${ }^{\circ}$ 10.753/2003 (Política Nacional do Livro) (BRASIL, 2003).
} 
Quando levamos em conta o Tratado de Marraquexe, além da visível disparidade entre um instrumento concebido para sanar a carência geral de livros e uma lei doméstica que favorece a manutenção desse impasse, é notável que, tal como a Lei de Direitos Autorais, a PNL restringe o acesso aos livros adaptados somente às pessoas cegas, sem levar em conta os beneficiários estabelecidos pelo Tratado de Marraquexe.

Além do exposto, faz-se mister ressaltar que inexiste previsão de trânsito não oneroso de livros em nível transnacional tanto na Lei de Direitos Autorais, quanto na redação da Política Nacional do Livro, bem como em normas correlatas, como é o caso da Política Nacional de Leitura e Escrita (Lei n ${ }^{\circ} 13.696$ de 2018), que se dispõe a viabilizar a inclusão de pessoas portadoras de deficiência visual nas iniciativas em prol da democratização do acesso aos livros mediante diretrizes postas por acordos, convenções e tratados internacionais, mas sem mencionar o câmbio internacional de livros constante no Tratado de Marraquexe (BRASIL, 2018b). ${ }^{25}$

Seguindo essa lógica, o Código Penal Brasileiro estabelece detenção de três meses até um ano ou multa em caso de violação dos direitos do autor, fazendo ressalva às exceções previstas na lei de direitos autorais, mas nenhum dos dois instrumentos contempla a reprodução e distribuição de livros em escala internacional como uma exceção às penalidades constantes do art. 184 do Código Penal (BRASIL, 1940). ${ }^{26}$

Depreende-se que, devido a condição de emenda constitucional dedicada ao Tratado de Marraquexe de 2013, consideram-se revogados, total ou parcialmente, os dispositivos anteriores à concepção da nova norma, que sejam inconciliáveis com a mesma. Logo, as exceções às normas expostas supra, que contemplam apenas pessoas cegas, devem passar a incluir, automaticamente, as demais categorias que constituem o grupo dos beneficiários, em respeito à normativa internacional específica e mais recente incorporada ao ordenamento brasileiro.

Contudo, a questão do intercâmbio transfronteiriço de exemplares adaptados, ao contrário da limitação aos direitos do autor, não encontra previsão alguma nas leis domésticas, bem como não existe a possibilidade legal do autor ser desvinculado das modificações da sua obra. Frente a essas vacuidades, foi aberta, pela Secretaria Especial da Cultura (SECULT), uma consulta pública, voltada à sociedade civil, buscando sugestões para compor a

${ }^{25}$ Art. $2^{\text {o da Lei n }}{ }^{\text {o }} 13.696$ (Política Nacional do Livro) (BRASIL, 2018b).

${ }^{26}$ Art. 184. do Decreto-Lei no 2.848 (Código Penal) (BRASIL, 1940). 
regulamentação do Tratado de Marraquexe de 2013. Uma minuta ao Decreto correspondente ao Tratado ( $n^{\circ} 9.522$ de 2018) está em fase de elaboração, visando a adequação total da legislação nacional ao compromisso assumido no âmbito da Organização Mundial da Propriedade Intelectual (BRASIL, 2020a).

Fala-se em adequação total, pois o Brasil já prevê limitações à sua lei de direitos autorais visando a reprodução gratuita de livros em formato adaptado, que é uma das principais determinações do Tratado de Marraquexe. Porém, as normas nacionais não contemplam o restante das obrigações do pacto, sendo identificado um cumprimento parcial do acordo transnacional, esperando-se que o pretendido decreto regulamentador atue como solucionador das incompletudes restantes.

\section{Conclusão}

É certo que a legislação brasileira guarda inconsistências em relação ao Tratado de Marraquexe de 2013, embora já exista uma iniciativa que poderá uniformizar, formalmente, a heterogeneidade de normas anteriores ao Tratado que são conflitantes com o mesmo. Nada obstante, é válido ressaltar que a adequação das leis domésticas à lei internacional é uma obrigação básica, em respeito ao que foi pactuado voluntariamente. Fato é que a entrada em vigor do Tratado deve provocar mudanças de cunho retroativo e evolucional, influindo sobre o que já foi feito e, na mesma medida, sobre o que será feito em relação aos direitos autorais e à circulação de obras escritas.

Resta claro, então, que existe um dever vitalício de respeitar o Tratado internacional internalizado. Entretanto, recentes proposições legislativas brasileiras mostram que o Tratado de Marraquexe, em que pese esteja em vias de ser regulamentado, não exerce influência alguma sobre novas iniciativas que impactam a proteção e o fluxo de obras escritas, a exemplo da reforma tributária pretendida pelo Ministério da Economia do atual governo (PEC 45/2019) (BRASIL, [2019?]). A reestruturação do sistema tributário acabará com a garantia constitucional de isenção de impostos para o mercado editorial, atrelando aos livros uma taxa de $12 \%$ (BRASIL, 2020b).

É urgente que seja levado em consideração o comprometimento do Estado brasileiro com a democratização da leitura, pois a ineficácia do Tratado de Marraquexe, dará continuidade à insuficiência de materiais de estudo e conhecimento às pessoas cegas no Brasil 
e no mundo, comprometendo o desenvolvimento pedagógico e social desse grupo, que depende diretamente da colaboração eficaz entre as nações pactuantes para vivenciarem mais acessibilidade no campo educativo e intelectual.

\section{REFERÊNCIAS}

BARBOSA, Denis Borges. Tratado da Propriedade Intelectual. 2. ed. Rio de Janeiro: Lumen Juris, 2019.

BARBOSA, Denis Borges. Uma Introdução à Propriedade Intelectual. Rio de Janeiro: Lumen Juris, 2003.

BRASIL. Câmara dos Deputados. Reforma Tributária: entenda a proposta. [S. l.: s. $n$., 2019?]. Disponível em: https://www.camara.leg.br/internet/agencia/infograficoshtml5/ReformaTributaria/index.html. Acesso em: 12 ago. 2020.

BRASIL. Constituição da República Federativa do Brasil de 1988. Brasília, DF:

Presidência da República, 1988. Disponível em:

http://www.planalto.gov.br/ccivil_03/constituicao/constituicao.htm. Acesso em: 01 ago. 2020.

BRASIL. Decreto no 75.572, de 08 de abril de 1975. Promulga a Convenção de Paris para a Proteção da Propriedade industrial revisão de Estocolmo, 1967. Brasília, DF: Câmara dos Deputados, 1975. Disponível em: https://www2.camara.leg.br/legin/fed/decret/1970-

1979/decreto-75572-8-abril-1975-424105-publicacaooriginal-1-pe.html. Acesso em: 12 jul. 2020 .

BRASIL. Decreto $\mathbf{n}^{\circ}$ 9.522, de 8 de outubro de 2018. Promulga o Tratado de Marraqueche para Facilitar o Acesso a Obras Publicadas às Pessoas Cegas, com Deficiência Visual ou com Outras Dificuldades para Ter Acesso ao Texto Impresso, firmado em Marraqueche, em 27 de junho de 2013. Brasília, DF: Presidência da República, 2018a. Disponível em:

http://www.planalto.gov.br/ccivil_03/_Ato2015-2018/2018/Decreto/D9522.htm. Acesso em: 12 jun. 2020.

BRASIL. Decreto-Lei no 2.848 , de 7 de dezembro de 1940. Código Penal. Rio de Janeiro, RJ: Presidência da República, 1940. Disponível em:

http://www.planalto.gov.br/ccivil_03/decreto-lei/del2848compilado.htm. Acesso em: 20 jul. 2020.

BRASIL. Lei $\mathbf{n}^{\mathbf{0}}$ 10.753, de 30 de outubro de 2003. Institui a Política Nacional do Livro. Brasília, DF: Presidência da República, 2003. Disponível em:

http://www.planalto.gov.br/ccivil_03/Leis/2003/L10.753.htm. Acesso em: 01 ago. 2020.

BRASIL. Lei $\mathbf{n}^{\mathbf{0}}$ 13.696, de 12 de julho de 2018. Institui a Política Nacional de Leitura e Escrita. Brasília, DF: Presidência da República, 2018b. Disponível em:

http://www.planalto.gov.br/ccivil_03/_ato2015-2018/2018/Lei/L13696.htm. Acesso em: 20 jul. 2020. 
BRASIL. Lei no 9.610, de 19 de fevereiro de 1998. Altera, atualiza e consolida a legislação sobre direitos autorais e dá outras providências. Brasília, DF: Presidência da República, 1998. Disponível em: https://www.planalto.gov.br/ccivil_03/leis/19610.htm. Acesso em: 02 jun. 2020.

BRASIL. Secretaria Especial da Cultura. SECULT abre consulta pública para a regulamentação do Tratado de Marraquexe. [S. l.: s. n.], 2020a. Disponível em: http://cultura.gov.br/secult-abre-consulta-publica-para-regulamentacao-do-tratado-demarraqueche/. Acesso em: 12 ago. 2020.

BRASIL. Secretaria Especial da Cultura. Sistema Nacional de Bibliotecas Públicas. Política Nacional de Leitura (PNLE). [S. l.: s. n., 2020?]. Disponível em: http://snbp.cultura.gov.br/pnle/. Acesso em: 20 jul. 2020.

BRASIL. Senado Federal. Reforma tributária pode fazer livro ficar mais caro. [S. l., s. n.], 2020b. Disponível em: https://www12.senado.leg.br/noticias/materias/2020/08/11/reformatributaria-pode-fazer-livro-ficar-mais-caro. Acesso em: 15 ago. 2020.

DREYFUSS, Rochelle; PILA, Justine. Intellectual Property Law: An Anatomical Overview. In: Intellectual Property Law: An Anatomical Overview. Oxford University Press, 2018.

LI, Jingyi. Facilitating Access to Digital Content for the Print Disabled: The Need to Expand Exemptions to Copyright Laws. Intellectual property journal, set. 2015, pp. 355-384, p. 383-384. Disponível em: https://www.researchgate.net/publication/283720813. Acesso em: 01 jul. 2021.

ORGANIZAÇÃO DAS NAÇÕES UNIDAS. Declaração Universal dos Direitos Humanos. [Paris: ONU, 1948]. Disponível em: https://nacoesunidas.org/wpcontent/uploads/2018/10/DUDH.pdf. Acesso em: 01 jul. 2021.

RODRIGUES, Daniela Oliveira. Limites aos Direitos do Autor. Rio de Janeiro: Lumen Juris, 2019.

SETOR3. 39\% das pessoas com deficiência visual costumam ler todos os dias. [S. l.: s. $n$.], 2019. Disponível em: setor3.com.br/39-das-pessoas-com-deficiencia-visual-costumam-lertodos-os-dias. Acesso em: 01 dez. 2021.

SEVILLE, Catherine. The Emergence and Development of Intellectual Property Law in Western Europe In: Intellectual Property Law: An Anatomical Overview. Oxford University Press, 2018.

TOKARNIA, Mariana. Braille: especialistas dizem que há avanços, mas ainda muito trabalho. Brasília: Agência Brasil, 2019. Disponível em: https://agenciabrasil.ebc.com.br/geral/noticia/2019-01/braille-especialistas-dizem-que-haavancos-mas-ainda-muito-trabalho. Acesso em: $01 \mathrm{dez} .2020$.

VIVANT, Michel; BRUGUIÈRE, Jean-Michel. Droit d'auteur. Paris: Dalloz, 2009. 
WORLD BLIND UNION. World Blind Union Guide to the Marrakesh Treaty. [S. l.: $s$. n.], 2016. Disponível em: http://www.worldblindunion.org/English/our-work/ourpriorities/Pages/WBU-Guide-to-the-Marrakesh-Treaty.aspx. Acesso em: 09 jul. 2021.

WORLD HEALTH ORGANIZATION. Blindness and vision impairment. [S. l.: s. $n$.], 2020. Disponível em: https://www.who.int/news-room/fact-sheets/detail/blindness-andvisual-impairment. Acesso em: 12 jun. 2021.

WORLD INTELLECTUAL PROPERTY ORGANIZATION. CHINA NATIONAL INTELLECTUAL PROPERTY ADMINISTRATION. World Intellectual Property Report Intellectual Property Basics: A Q\&A for Students. Geneva: WIPO Publication, 2019. Disponível em: https://www.wipo.int/edocs/pubdocs/en/wipo_pub_1056.pdf. Acesso em: 02 jun. 2021.

WORLD INTELLECTUAL PROPERTY ORGANIZATION. Main Provisions and Benefits of the Marrakesh Treaty (2013). Geneva: WIPO Publications, 2016. Disponível em: https://www.wipo.int/edocs/pubdocs/en/wipo_pub_marrakesh_flyer.pdf. Acesso em: 12 jun. 2021.

WORLD INTELLECTUAL PROPERTY ORGANIZATION. The Marrakesh Treaty to Facilitate to Published Works for Persons Who Are Blind, Visually Impaired, or Otherwise Print Disabled. Marrakesh: [s. n.], 2013. Disponível em: https://wipolex.wipo.int/en/text/301016. Acesso em: 02 jun. 2021.

WORLD INTELLECTUAL PROPERTY ORGANIZATION. What is Intellectual Property?. Geneva:WIPO Publications, 2020. Disponível em:

https://www.wipo.int/edocs/pubdocs/en/intproperty/450/wipo_pub_450.pdf. Acesso em: 12 jun. 2021.

WORLD INTELLECTUAL PROPERTY ORGANIZATION. WIPO - A Brief History. [S. l.: s. $n ., 2020 \mathrm{a}]$. Disponível em: https://www.wipo.int/about-wipo/en/history.html. Acesso em: 25 out. 2021.

WORLD INTELLECTUAL PROPERTY ORGANIZATION. WIPO-Administered Treaties. [S. l.: s. n., 2020b]. Disponível em: https://www.wipo.int/treaties/en/. Acesso em: 27 out. 2021. 